\title{
O Conceito de Representação Social na Abordagem Psicossocial
}

\section{The Concept of Social Representations in Social Psychology}

\begin{abstract}
Mary Jane P. Spink ${ }^{1}$
SPINK, M. J. P. The Concept of Social Representations in Social Psychology. Cad. Saúde Públ., Rio de Janeiro, 9 (3): 300-308, jul/sep, 1993.

Taking as a starting point the definition of social representation as a form of practical knowledge, this paper aims at situating the social psychology approach among the other disciplines which deal with the issue of knowledge. Accepting the implicit interdisciplinarity of this field of study, the paper analyzes both the common aspects of the field and the specific contribution of social psychology. In the transdisciplinary perspective, social representations emerge as a multidimensional concept which allows for a critical analysis of both the nature of knowledge and the relationship between the individual and society demonstrating its compatibility with post-modern epistemology. The specific contribution of social psychology is analyzed first from a theoretical point of view, emphasizing social psychology's vocation for studying social representations as socially structured fields which have structuring effects on social reality. Second, the methodological contribution is discussed with special emphasis on the use of qualitative methodologies, and more specifically the use of single case studies.
\end{abstract}

Key words: Social Representation; Social Psychology; Knowledge; Constructivism

\section{INTRODUÇÃO}

As representações sociais, segundo definição clássica apresentada por Jodelet (1985), são modalidades de conhecimento prático orientadas para a comunicação e para a compreensão do contexto social, material e ideativo em que vivemos. São, conseqüentemente, formas de conhecimento que se manifestam como elementos cognitivos - imagens, conceitos, categorias, teorias —, mas que não se reduzem jamais aos componentes cognitivos. Sendo socialmente elaboradas e compartilhadas, contribuem para a construção de uma realidade comum, que possibilita a comunicação. Deste modo, as representações são, essencialmente, fenômenos sociais que, mesmo acessados a partir do seu conteúdo cognitivo, têm de ser entendidos a partir do seu contexto de produção. Ou seja, a

\footnotetext{
Programa de Estudos Pós-Graduados em Psicologia Social da Pontifícia Universidade Católica de São Paulo. Rua Monte Alegre 984, São Paulo, SP, 05014-001, Brasil.
}

partir das funções simbólicas e ideológicas a que servem e das formas de comunicação onde circulam.

Sendo formas de conhecimento, as representações sociais constituem uma vertente teórica da Psicologia Social que faz contraponto com as demais correntes da Filosofia, da História, da Sociologia e da Psicologia Cognitiva que se debruçam sobre a questão do conhecimento. Situá-las na ótica da Psicologia Social implica, portanto, discutir tanto aquilo que é compartilhado pelas demais disciplinas - e que faz das representações sociais um campo transdisciplinar — quanto a contribuição específica da Psicologia Social.

\section{AS REPRESENTAÇÕES SOCIAIS ENQUANTO CONCEITO TRANSDISCIPLINAR}

Pensando primeiramente na transversalidade das representações sociais, não há dúvida de que, estando situada na interface dos fenômenos individual e coletivo, esta noção tem, como 
aponta Jodelet (1989a), a vocação de interessar a todas as ciências humanas.

Numa tentativa de pontuar as diferenças, pensando mais especificamente nas abordagens da Psicologia e da Antropologia, Sperber (1989) introduz a questão do nível de análise. As representações, segundo o autor, podem ser abordadas, enquanto eventos intra-individuais, como representações mentais, estudadas pela Psicologia Cognitiva e pela Psicanálise, onde o social é apenas uma sombra; como elementos centrais da comunicação, sendo então representações públicas, objeto de estudo da Psicologia Social; ou, ainda, como elementos coletivos, comunicados repetidamente e distribuídos igualmente numa determinada formação social, sendo então representações culturais, objeto de estudo da Antropologia. Usando metáforas médicas, Sperber avança no esforço comparativo, assemelhando a Antropologia à Epidemiologia: uma disciplina interessada na distribuição das representações em uma determinada população. Já a Psicologia assemelhar-se-ia à Patologia, dedicando-se ao estudo das representações propriamente ditas: seu conteúdo e seu processo de elaboração.

Outra maneira de entender a transdisciplinaridade aí implícita seria procurando explicitar as múltiplas dimensões do campo de estudos das representações sociais (Figura 1). Esta perspectiva, adotada por Jodelet (1989a), tem a vantagem de abandonar a divisão de territórios disciplinares e assinalar a importância da definição precisa do aspecto a ser abordado no estudo das representações sociais.

A Figura 1, uma simplificação de um esquema apresentado por Jodelet (1989a), nos permite visualizar os dois eixos principais deste campo de estudos: no primeiro eixo, as representações constituem formas de conhecimento prático orientadas para a compreensão do mundo e para a comunicação; no segundo eixo, elas emergem como elaborações (construções de caráter expressivo) de sujeitos sociais a respeito de objetos socialmente valorizados. As duas dimensões descortinam pressupostos de natureza epistemológica sobre a natureza do conhecimento.

FIGURA 1. O Campo de Estudos da Representação Social

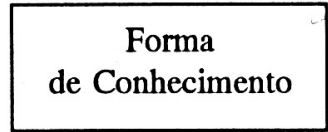

Construção

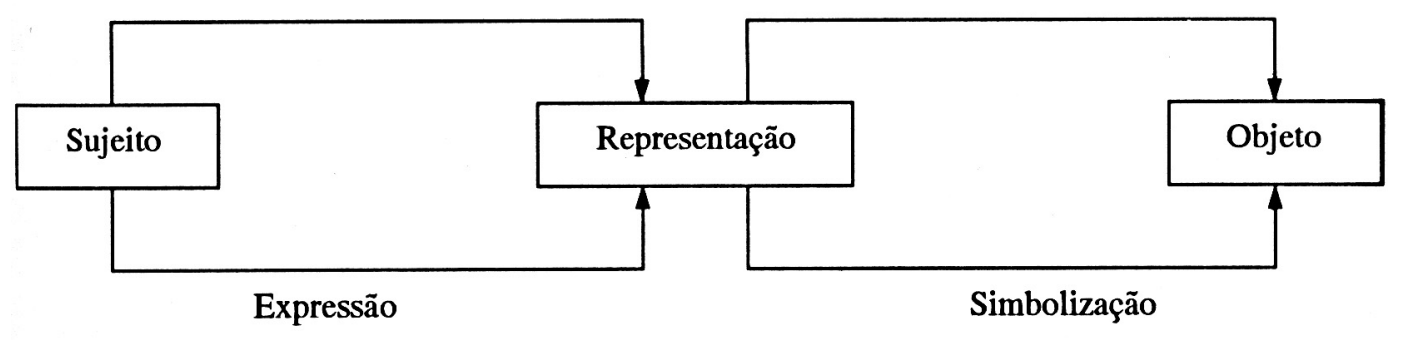

Prático

Adaptado de Jodelet (1989a). 


\section{As Representações Sociais como Formas de Conhecimento}

Buscando situar as representações sociais entre as correntes mais tradicionais das teorias do conhecimento, vale recorrer, como ponto de partida, ao vernáculo. Excetuando-se o sentido jurídico do termo "representação", o Dicionário Aurélio (Ferreira, 1975) oferece duas definições, que revelam o embate epistemológico implícito nesta noção.

Num primeiro sentido, representação é o “conteúdo concreto apreendido pelos sentidos, pela imaginação, pela memória ou pelo pensamento"; é, em síntese, a "reprodução daquilo que se pensa" (Ferreira, 1975). Nesta definição, a ênfase situa-se na natureza do conhecimento, na possibilidade mesmo do conhecimento e da apreensão da realidade. Esta vertente nos remete aos estudos clássicos sobre ideologia e às brechas irreparáveis introduzidas aí pelo historicismo, pelo relativismo cultural e pela arqueologia foucaultiana, que abrem caminho para o paradigma construtivista.

As representações sociais, sendo definidas como formas de conhecimento prático, inseremse mais especificamente entre as correntes que estudam o conhecimento do senso comum. Tal privilégio já pressupõe uma ruptura com as vertentes clássicas das teorias do conhecimento, uma vez que estas abordam o conhecimento como saber formalizado, isto é, focalizam o saber que já transpôs o limiar epistemológico, sendo constituídas por conjuntos de enunciados que definem normas de verificação e coerência. Em nítido contraste, as correntes que se debruçam sobre os saberes enquanto saberes, quer formalizados ou não, procuram superar a clivagem entre ciência e senso comum, tratando ambas as manifestações como construções sociais sujeitas às determinações sócio-históricas de épocas específicas.

É óbvio que esta diferenciação não é um mero artifício didático; é óbvio que ela implica a constatação de importantes mudanças no posicionamento quanto ao estatuto da objetividade e da busca da verdade. Trata-se, evidentemente, de inserir o estudo das representações sociais entre os esforços de desconstrução da retórica da verdade, componente intrínseco da Revolução Científica que inaugura a moder- nidade nas sociedades ocidentais. Esta contestação da retórica da verdade pode ser visualizada como um movimento em três tempos: da epistemologia clássica à incorporação do social, com a consequiente relativização da objetividade, e, no terceiro momento, à ampliação do olhar, de modo a ver o senso comum não mais como cidadão de segunda classe, mas como conhecimento legítimo e motor das transformações sociais.

Assim, segundo Fuller (1988),

“a epistemologia clássica parecia viável exatamente porque pensava-se existirem 'verdades' cuja aceitação beneficiaria a todos —ou, pelo menos, a todos os seres racionais e conseqüentemente não tinham efeitos globais na distribuição do poder. Esta é uma maneira de expressar a ‘neutralidade’ do conhecimento científico. Ou seja, embora este conhecimento possa ser usado de forma a promover determinados valores, $o$ conhecimento, enquanto tal, não é viesado a favor ou contra a realização de valores particulares"

Já a Sociologia do Conhecimento, inaugurada por Scheler, nos anos 20, e elevada ao estatuto de disciplina por Mannheim, nos anos 30, vira de ponta-cabeça a questão da neutralidade do conhecimento. Como aponta Fuller (1988), "se a concessão de garantia epistemológica envolve, entre outras coisas, a aceitação social, e um dos benefícios chave dessa concessão é o poder de fazer pronunciamentos autoritativos, então, conceder o selo de garantia epistemológica é uma forma encoberta de distribuir poder." A ideologia, neste contexto, não pode mais ser vista como ilusão, mistificação ou falsa consciência. Precisa ser vista como instrumento de dominação. Mesmo assim, a clivagem entre ciência /verdade e senso comum/ilusão permanece intata. $\mathrm{O}$ objeto de estudo é ainda o conhecimento formalizado em disciplinas científicas. Introduz-se, sim, a questão do poder, ou dos interesses; mas poder e interesses são ainda abordados a partir da perspectiva do campo científico.

O terceiro movimento introduz uma nova perspectiva, ampliando o conhecimento-objeto de estudo para além da fronteira da história das 
idéias. Passa a abarcar, também, ou melhor, sobretudo, o conhecimento do homem comum. Neste terceiro movimento, o que está em pauta é o desvelamento da teia de significados que sustenta nosso cotidiano e sem a qual nenhuma sociedade pode existir. É este alargamento do campo de interesses que torna possível uma arqueologia das idéias, no sentido foucaultiano, que se contrapõe à história epistemológica.

Esta mudança de perspectiva quanto ao papel disciplinador das teorias do conhecimento, de um lado legitimando o saber não consubstanciado em disciplinas científicas e, de outro, pondo na berlinda o selo de garantia epistemológica, teve um papel fundamental na elaboração do conceito de representações sociais em Psicologia Social. Teve, antes de mais nada, o efeito de liberar o poder de criação dos conhecimentos práticos, ou das teorias do senso comum, tão freqüentemente aprisionados nos chavões de reprodução ou de (re)apresentação. Ou seja, não se trata, neste terceiro movimento das teorias do conhecimento, de reabilitar o senso comum enquanto forma válida de conhecimento; trata-se, sobretudo, de situá-lo como teia de significados capaz de criar efetivamente a realidade social.

Moscovici (1988) reconhece amplamente que, ao enfatizar o poder de criação das representações sociais, acatando sua dupla face de estruturas estruturadas e estruturas estruturantes, inscreve sua abordagem entre as perspectivas construtivistas. Inscreve-a, entretanto, no movimento maior, aqui denominado terceiro movimento das teorias do conhecimento. Aponta, assim, a simultaneidade, ou, até mesmo, a anterioridade, de sua obra e da obra de Berger \& Luckmann (1966), que cunhou a perspectiva denominada "construção social da realidade".

Retornando ao vernáculo, se o primeiro sentido atribuído à palavra "representação" permitiu-nos situar os pressupostos epistemológicos do estudo das representações sociais, o segundo sentido nos aproxima mais do teatro e, como tal, de uma teoria da ação. Segundo o Dicionário Aurélio (Ferreira, 1975), representação é também o "ato ou efeito de representar(-se)", é uma "interpretação". Nesta perspectiva, não é mais a natureza do conhecimento expresso em representações que está em pauta, porém suas implicações práticas. Neste sen- tido, reportando-nos a Wittgenstein (1953) e aos interacionistas simbólicos por ele influenciados, somos atores sociais engajados na construção de identidades funcionais que nos permitem negociar as relações sociais.

Este segundo sentido abre caminho para as modernas análises de discurso (Edwards \& Potter, 1992), onde a ênfase não recai mais na estrutura lingüística ou nos conteúdos cognitivos, mas na organização social do discurso. Deixa, assim, de existir qualquer separação entre linguagem e ação, seja pela mediação cognitiva ou pela mediação do contexto social, pois a linguagem é tomada como sendo concomitantemente ato.

Partindo das considerações sobre o primeiro eixo apresentado na Figura 1, deparamo-nos com duas maneiras muito distintas de adentrar este campo de estudos. Numa primeira vertente, é o estatuto do conhecimento que está em pauta: sua natureza e seus pressupostos epistemológicos. Já na segunda vertente, a ênfase é na funcionalidade. $\mathrm{O}$ conhecimento estudado via representações sociais é sempre um "conhecimento prático"; é sempre uma forma comprometida e/ou negociada de interpretar a realidade. Nesta segunda vertente, a tendência tem sido de eliminar a expressão "representação social", adotando, em seu lugar, a expressão "práticas discursivas", numa tentativa de eliminar a confusão seminal do conceito de representação social, que, inevitavelmente, situa-se entre dois paradigmas: o da modernidade e o da pósmodernidade.

\section{O Sujeito como Produto e Produtor da Realidade Social}

O segundo eixo da Figura 1 nos remete, necessariamente, à atividade do sujeito tomado como indivíduo ou grupo - na elaboração das representações sociais. Ou seja, a representação é uma construção do sujeito enquanto sujeito social. Sujeito que não é apenas produto de determinações sociais nem produtor independente, pois que as representações são sempre construções contextualizadas, resultados das condições em que surgem e circulam.

É, ainda, uma expressão da realidade intraindividual, uma exteriorização do afeto. Con- 
forme diz Jodelet (1989a), "as representações sociais devem ser estudadas articulando elementos afetivos, mentais, sociais, integrando a cognição, a linguagem e a comunicação às relações sociais que afetam as representações sociais e à realidade material, social e ideativa sobre a qual elas intervêm".

Dois aspectos são particularmente relevantes neste segundo eixo do campo de estudos das representações sociais. Em primeiro lugar, o posicionamento sobre a relação indivíduosociedade, que foge tanto ao determinismo social - onde o homem é produto da sociedade - quanto ao voluntarismo puro, que vê o sujeito como livre agente. Busca um posicionamento mais integrador que, embora situando o homem no processo histórico, abre lugar para as forças criativas da subjetividade. Em segundo lugar, ao abrir espaço para a subjetividade, traz para o centro da discussão a questão do afeto: as representações não são, assim, meras expressões cognitivas; são permeadas, também, pelo afeto.

Por que construções? Porque as representações, sendo sempre representações de um sujeito sobre um objeto, não são nunca reproduções deste objeto. Como indica a Figura 1, as representações são interpretações da realidade. Dito de outra forma, a relação com o real nunca é direta; é sempre mediada por categorias histórica e subjetivamente constituídas. Neste sentido, o construtivismo inerente à abordagem das representações sociais em Psicologia Social faz eco aos desenvolvimentos mais recentes no campo da ciência, caminho aberto pelas revoluções na Física, a partir da constituição da Física Quântica, que resultararam, como aponta Birman (1991), "na colocação paulatina do sujeito do conhecimento no primeiro plano da produção do objeto teórico dos diferentes discursos científicos. Estes passam a ser considerados como produções históricas e não a enunciação de verdades universais". E, seguindo ainda o raciocínio do autor, "reconhecer no registro epistemológico a posição do sujeito na produção do objeto teórico da ciência é afirmar, ao mesmo tempo, que este sujeito empreende um trabalho de interpretação do real e que a interpretação é constitutiva da objetividade científica".

\section{A ESPECIFICIDADE DA ABORDAGEM DA PSICOLOGIA SOCIAL}

Tendo situado as representações sociais no conjunto das disciplinas que se debruçam sobre a construção do conhecimento e delineado alguns pressupostos básicos que as inserem nas correntes pós-modernas, resta-nos caracterizálas enquanto abordagem psicossocial. Em se tratando de um campo de estudo transdisciplinar, mas sem cair na armadilha da compartimentalização disciplinar, cabe-nos, inevitavelmente, destacar a contribuição da Psicologia Social, especialmente no que tange ao esforço de superar a dicotomia entre indivíduo e sociedade, e entre psicologismo e sociologismo.

De modo geral, como aponta Fuller (1988), "o psicologismo (...) envolve a avaliação do estado mental que o produtor traz para o processo de conhecimento, enquanto o sociologismo (...) envolve a avaliação das conseqüências do processo de conhecimento - os produtos do conhecimento - sem levar em consideração os estados mentais do produtor". Desta forma, o sociólogo será antipsicologista se seu relato não demandar que os agentes sociais em pauta tenham qualquer conteúdo mental privado, tal como desejos e crenças, que possa por em dúvida as expectativas de papel publicamente definidas. O psicólogo, por sua vez, incorrerá em antisociologismo quando não levar em conta os efeitos da presença real, imaginada ou intuída de outros.

A Psicologia Social procura superar esta dicotomia visualizando o indivíduo e suas produções mentais como produtos de sua socialização em um determinado segmento social. A individualidade, nesta perspectiva, emerge como uma estrutura estruturada que tem potencial estruturante.

Retornando, então, às representações sociais, isto equivale a dizer que estas formas de pensamento prático são, concomitantemente, campos socialmente estruturados que só podem ser compreendidos quando referidos às condições de sua produção e aos núcleos estruturantes da realidade social, tendo em vista seu papel na criação desta realidade. 


\section{As Representações Sociais enquanto Campos Socialmente Estruturados}

As representações sociais, sendo produzidas e apreendidas no contexto das comunicações sociais, são necessariamente estruturas dinâmicas. É esta característica de flexibilidade e permeabilidade que as distingue, conforme afirma Moscovici (1989), das representações coletivas de Durkheim ou, mesmo, das representações culturais de Sperber (1989). É esta característica, ainda, que as aproxima das modernas análises de discurso influenciadas por Wittgenstein (1953), que, centradas na relação íntima entre linguagem e ação, focalizam justamente esta permeabilidade e esta flexibilidade.

Entretanto - e paradoxalmente - , o estudo empírico das representações sociais revela, freqüentemente, a concomitância de conteúdos mais estáveis e de conteúdos dinâmicos, mais sujeitos à mudança. As representações sociais, portanto, são tanto a expressão de permanências culturais como são o locus da multiplicidade, da diversidade e da contradição. Dito de outra forma, como pode ser visualizado na Figura 2, as representações sociais são campos socialmente estruturados na interface de contextos sociais de curto e longo alcances históricos.
No modelo proposto na Figura 2, o contexto social de longo alcance foi denominado imaginário social, definido aqui como a "teia de significados tecidos pelo homem ao longo da história da espécie" (Geerz, 1978). O imaginário social seria, assim, o conjunto cumulativo das produções culturais que circulam numa determinada sociedade sob formas as mais variadas: iconografia, literatura, canções, provérbios, mitos. Estas produções são filtradas pelas representações hegemônicas constitutivas da epistéme (Foucault, 1987), ou visão de mundo, de uma determinada época histórica. São, ainda, reinterpretadas pelo grupo, ou, mais especificamente, pelo habitus, entendido, conforme definido por Bourdieu (1983), como disposições adquiridas em função de se pertencer a determinados grupos sociais.

Entretanto, as representações sociais não são meras (re)combinações de conteúdos arcaicos sob pressão das forças do grupo. Elas são também alimentadas pelos produtos da ciência, que circulam publicamente através da mídia e das inúmeras versões populares destes produtos.

A co-existência de permanências e novidade no campo socialmente estruturado permite entender melhor a questão da diversidade. Como aponta Geerz (1983), ao trabalharmos

FIGURA 2. As Representações Sociais no Contexto da Teia de Significados Construídos pelo Homem ao Longo da História

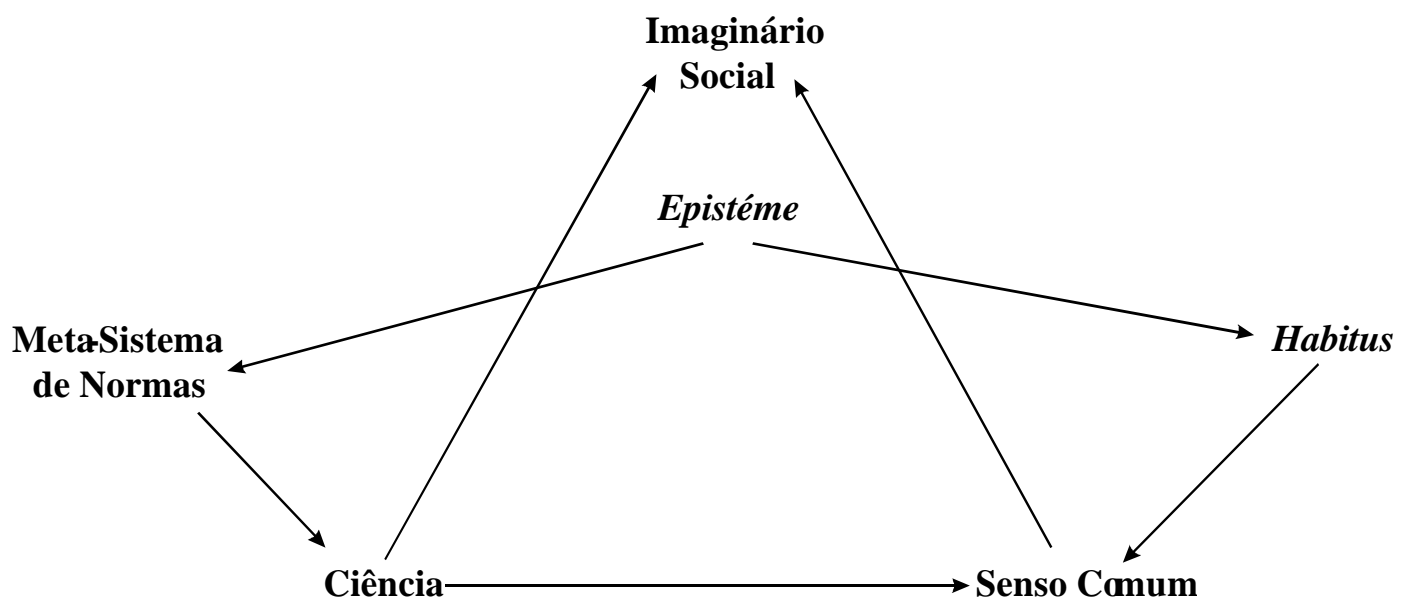


com o senso comum, não nos cabe catalogar os conteúdos em busca do estável e do consensual, porque eles são essencialmente heterogêneos. Não nos cabe, também, buscar as estruturas lógicas subjacentes, porque elas não existem. Ao aprofundarmos a análise do senso comum, deparamo-nos não com a lógica e com a coerência, mas com a contradição.

Aceitar a diversidade implícita do senso comum, entretanto, não significa abrir mão do consenso, pois algo sempre sustenta uma determinada ordem social: pressupostos de natureza ideológica, epistémes historicamente localizadas ou, até mesmo, ressonâncias do imaginário social. Afinal, as representações são elaboradas a partir de um campo socialmente estruturado e são frutos de um imprinting social. Mas, como aponta Morin (1983), há zonas fracas neste imprinting que permitem com que haja movimento, mudança, abertura à novidade, novas formas de ancorar fatos pouco familiares.

Ou seja, parece lícito afirmar que, se de um lado buscamos os elementos mais estáveis, aqueles que permitem a emergência de identidades compartilhadas, de outro trabalhamos com o que há de diferente, diverso e contraditório no fluxo do discurso social.

\section{As Representações Sociais enquanto Núcleos Estruturantes}

A diversidade e a contradição nos remetem ao estudo das representações sociais não mais como conteúdos, mas como processo. Processo entendido não como mero processamento de informações e elaboração de teorias, mas como práxis; ou seja, tomando como ponto de partida a funcionalidade das representações sociais na criação e na manutenção de uma determinada ordem social.

Nos diversos textos que lidam com as representações sociais enquanto formas de conhecimento prático, são destacadas diversas funções, entre elas: orientação das condutas e das comunicações (função social); proteção e legitimação de identidades sociais (função afetiva) e familiarização com a novidade (função cognitiva).

A função cognitiva de familiarização com a novidade, transformando o estranho - potencialmente ameaçador — em algo familiar, nos permite evidenciar os dois principais processos envolvidos na elaboração das representações postulados por Moscovici em 1961: ancoragem e objetivação. A ancoragem refere-se à inserção orgânica do que é estranho no pensamento já constituído. Ou seja, ancoramos o desconhecido em representações já existentes. Moscovici (1978) a concebe como um processo de domesticação da novidade sob a pressão dos valores do grupo, transformando-a em um saber capaz de influenciar, pois "nos limites em que ela penetrou numa camada social, também se constitui aí num meio capaz de influenciar os outros e, sob esse aspecto, adquire status instrumental". Em suma, a ancoragem é feita na realidade social vivida, não sendo, portanto, concebida como processo cognitivo intra-individual.

A cristalização de uma representação nos remete, por sua vez, ao segundo processo : a objetivação. A objetivação é essencialmente uma operação formadora de imagens, o processo através do qual noções abstratas são transformadas em algo concreto, quase tangível, tornando-se "tão vívidos que seu conteúdo interno assume o caráter de uma realidade externa" (Moscovici, 1988). Este processo implica três etapas: primeiramente, a descontextualização da informação através de critérios normativos e culturais; em segundo lugar, a formação de um núcleo figurativo, a formação de uma estrutura que reproduz de maneira figurativa uma estrutura conceitual; e, finalmente, a naturalização, ou seja, a transformação destas imagens em elementos da realidade.

É óbvio, assim, que a ênfase dada à função cognitiva, por mais que procure preservar a realidade vivida e não reduzir a elaboração das representações a processos cognitivos, acaba por privilegiar tais processos. Já a função afetiva de proteção de identidades nos remete à dinâmica da interação social e, mais especificamente, à elaboração de estratégias coletivas ou individuais para a manutenção das identidades ameaçadas. O estudo de Jodelet (1989b) sobre as representações da loucura numa comunidade rural, onde era desenvolvido um sistema de albergamento de pacientes egressos de hospitais psiquiátricos, constitui um excelente exemplo da funcionalidade das representações para a 
manutenção da identidade grupal e para a defesa contra a ansiedade suscitada pela proximidade à doença mental.

Por fim, a função social exige uma análise mais microscópica das trocas sociais, tais como efetuadas na Psicologia Discursiva (Edwards \& Potter, 1992) ou na Etnometodologia, de tal forma que seja evidenciado o processo de negociação constitutivo das relações sociais.

Ao trabalharmos com o processo, distanciamo-nos da perspectiva epidemiológica a que se referia Sperber (1989), que busca a distribuição de conteúdos numa dada população. Quando a diversidade e o processo são privilegiados, quando o conteúdo é mera estratégia para acessar o processo de elaboração, abre-se então a possibilidade de trabalharmos com estudos de caso. O indivíduo, nesta perspectiva, seguindo a tradição vigotskiana (Vigoysky, 1978), é sempre uma entidade social e, como tal, um símbolo vivo do grupo que ele representa. Assim, o indivíduo no grupo, próprio das abordagens quantitativas, pode ser abordado como sujeito genérico - como o grupo no indivíduo - , contanto que tenhamos uma compreensão adequada do contexto social por ele habitado: seu habitus e a teia mais ampla de significados na qual o objeto de representação está localizado. É esta, possivelmente, a contribuição mais valiosa da Psicologia Social para o estudo das representações sociais: a ênfase no processo de elaboração das representações a partir das práticas sociais que as definem e que são por elas definidas, bem como a abertura da possibilidade de se trabalhar o particular como expressão do universal, através de estudos de caso social e historicamente contextualizados.

\section{CONCLUSÃO}

As múltiplas dimensões do campo de estudos das representações sociais, a interdisciplinaridade que lhe é intrínseca, as contradições e paradoxos com que se depara o pesquisador e as inúmeras dualidades (campo estruturado/núcleo estruturante; conteúdo/processo; contexto histórico/ "aqui-e-agora"), que, a exemplo das unidades subatômicas estudadas pela Física Quântica, têm um aspecto dual, apresentando-se ora como partículas, ora como ondas, situam as representações sociais no seio do debate mais atual sobre a ciência, não só pelo questionamento que suscita sobre a natureza do conhecimento e sobre a relação indivíduo-sociedade, mas, sobretudo, por inseri-la dentro do paradigma da complexidade (Morin, 1983).

Não se trata de buscar uma síntese, mas de aceitar e trabalhar com a polifasia. Como diz Morin (1984),

"o que me interessa não é uma síntese, mas um pensamento transdisciplinar, um pensamento que não se quebre nas fronteiras entre as disciplinas. $O$ que me interessa é $o$ fenômeno multidimensional, e não a disciplina que recorta uma dimensão nesse fenômeno. Tudo o que é humano é ao mesmo tempo psíquico, sociológico, econômico, histórico, demográfico. É importante que estes aspectos não sejam separados, mas sim que concorram para uma visão poliocular. $O$ que me estimula é a preocupação de ocultar o menos possível a complexidade do real" (grifo nosso).

\section{RESUMO}

\section{SPINK, M. J. P. O Conceito de}

Representação Social na Abordagem

Psicossocial. Cad. Saúde Públ., Rio de Janeiro, 9 (3): 300-308, jul/set, 1993.

Partindo da definição de representação social como forma de conhecimento prático, este artigo procura situar a abordagem da Psicologia Social entre as demais correntes que se debruçam sobre a questão do conhecimento. Acatando a interdisciplinaridade intrínseca ao campo de estudos das representações sociais, são analisados tanto os aspectos comuns às diversas disciplinas como a contribuição específica da Psicologia Social. $\mathrm{Na}$ perspectiva transdisciplinar, as representações sociais emergem como um campo multidimensional que possibilita questionar, de um lado, a natureza do conhecimento e, de outro, a relação indivíduo-sociedade, inserindo este campo de estudos entre as correntes epistemológicas pós-modernas. A contribuição 
específica da Psicologia Social é analisada, num primeiro momento, do ponto de vista teórico, sendo enfatizada a vocação desta disciplina de trabalhar as representações simultaneamente como campos socialmente estruturados e núcleos estruturantes da realidade social. Num segundo momento é destacada a contribuição metodológica que abre espaço para a utilização de metodologias qualitativas e, mais especificamente, para o uso do caso único.

Palavras-Chave: Representação Social; Psicologia Social; Conhecimento; Construtivismo

\section{REFERÊNCIAS BIBLIOGRÁFICAS}

BERGER, P. \& LUCKMANN, T., 1966. The Social Construction of Reality. Garden City: Doubleday.

BIRMAN, J., 1991. Interpretação e realidade na Saúde Coletiva. Physis, Revista de Saúde Coletiva, 1: 7-22.

BOURDIEU, P., 1983. Questões de Sociologia. Rio de Janeiro: Marco Zero.

EDWARDS, D. \& POTTER, J., 1992. Discursive Psychology. Londres: Sage.

FERREIRA, A. B. H., 1975. Novo Dicionário Aurélio da Língua Portuguesa. Rio de Janeiro: Nova Fronteira.

FOUCAULT, M., 1987. A Arqueologia do Saber. Rio de Janeiro: Forense Universitária.

FULLER, S., 1988. Social Epistemology. Bloomington and Indianapolis: Indiana University Press.
GEERZ, C., 1978. A Interpretação das Culturas. Rio de Janeiro: Zahar. , 1983. Local Knowledge. Basic Books.

JODELET, D., 1985. La representación social: Fenómenos, concepto y teoría. In: Psicologia Social (S. Moscovici, org.), pp. 469-494, Barcelona: Paídos.

, 1989a. Représentations sociales: un domain en expansion. In: Les Représentations Sociales (D. Jodelet, org.), pp. 31-61, Paris: Presses Universitaires de France. 1989b. Folies et Représentations Sociales. Paris: Presses Universitaires de France.

MORIN, E., 1983. O Problema Epistemológico da Complexidade. Lisboa: Europa-América. , 1984. Idéias Contemporâneas - Entrevistas do Le M onde. São Paulo: Ática.

MOSCOVICI, S., 1978. A Representação Social da Psicanálise. Rio de Janeiro: Zahar. , 1988. Notes towards a description of social representations. European Journal of Social Psychology, 18: 211-250. , 1989. Des représentations collectives aux représentations sociales. In: Les Représentations Sociales (D. Jodelet, org.), pp. 62-86, Paris: Presses Universitaires de France.

SPERBER, D., 1989. Létude anthropologique des représentations. In: Les Représentations Sociales (D. Jodelet, org.), pp. 113-130, Paris: Presses Universitaire de France.

VIGOTSKY, L. S., 1978. M ind in Society. Cambridge: Harvard University Press.

WITTGENSTEIN, L., 1953. Phylosophical Investigations. Oxford: Basil Blackwell. 